\title{
Role of endocrine status and cell type in adhesion of human endometrial cells to the peritoneum in nude mice ${ }^{1}$
}

Aude Beliard, M.D., Agnes Noël, Ph.D., Frederic Goffin, M.D., Francis Frankenne, Ph.D., and Jean-Michel Foidart, M.D., Ph.D.

Laboratory of Biology of Tumors and Development, University of Liège, Liège, Belgium

\begin{abstract}
Objective: To investigate the role of different cellular types (epithelial and stromal endometrial cells and peritoneal cells) in the ectopic implantation of endometrium and to evaluate the importance of endocrine environment on the adhesion of endometrial cells to the peritoneum.
\end{abstract}

Design: Experimental prospective study.

Setting: University hospital, department of cell biology.

Animal(s): One hundred one nude mice.

Intervention(s): Monolayer culture of human epithelial and stromal endometrial cells obtained from patients undergoing hysterectomy or laparoscopy for benign disease. Intraperitoneal injection of cells into nude mice.

Main Outcome Measure(s): Two weeks after cell injection, adhesion of endometrial cells was evaluated by histological and immunohistochemical examination.

Result(s): Mixed cultures of stromal and epithelial cells, but not purified epithelial or stromal cells alone, adhered to the mouse peritoneum and led to endometriotic-like nodules. Pretreatment of cells with estrogen alone or with estrogen and progestin resulted in a higher percentage of animals developing endometriotic-like nodules, whereas treatment with progestin alone did not affect endometriotic implantation.

Conclusion(s): Our data indicate that the success of endometrial cell implantation is dependent on the cooperativeness between stromal and epithelial endometrial cells, as well as on the endocrine environment of endometrial cells, but not that of recipient animals. The results emphasize the role of both endometrial cell types for ectopic implantation.

Key Words: Endometriosis, human reproduction, nude mice

Endometriosis is characterized by the proliferation of endometrial glands and stroma outside the uterine cavity. The pathology origin is explained by the theory of celomic metaplasia (1) or by the retrograde menstruation or implantation theory (2). The latter theory is more commonly accepted and is supported by circumstantial evidence $(3,4)$. The implantation theory is based on the assumption that viable endometrial cells from retrograde menstruation reach the abdominal cavity, implant, and grow to some extent on the peritoneum. Previous studies have demonstrated the viability of sloughed endometrial cells in menstrual fluid $(5,6)$. However, the mechanism by which endometrial cells adhere to the peritoneal lining is not yet known.

Several etiologic factors have been proposed that may contribute to the development of endometriosis such as an imbalance of local environmental factors of the peritoneal compartment, alterations of the peritoneal lining (6), or abnormal immunologic defense mechanisms (7). The respective contribution of stromal and epithelial

\footnotetext{
1 This work was supported by grants from the Communauté Française de Belgique (Actions de Recherches Concertées), the Commission of European Communities, the Fonds de la Recherche Scientifique Médicale, the Fonds National de la Recherche Scientifique (FNRS, Belgium), the Fédération Belge Contre le Cancer, the Fonds spéciaux de la Recherche (University of Liège), the Centre Anticancéreux près l'Université de Liège, the CGER-FORTIS-Assurances, the Fondation Léon Frédéricq (University of Liège), the DGTRE from the "Région Wallonne", the Fonds d'Investissements de la Recherche Scientifique (CHU, Liège, Belgium), and General RE-Luxembourg. AN is a senior associate researcher and FG is an assistant researcher at the FNRS (Belgium).
} 
endometrial cells or that of the mesothelium in the development of endometriosis is not yet established. Although various models have been developed in mice to study endometrial adhesion to the peritoneal lining, most investigators used fresh endometrial fragments $(6,8-10)$ or organ cultures $(11,12)$. Until now, the use of dispersed cells was not successful $(13,14)$ and hormonal environment was never taken into account.

The present study is original in its use of mixed cultures of stromal and epithelial endometrial cells or cultures of isolated pure epithelial or stromal endometrial cells. Our aim was to evaluate the adhesion of those cultures to the peritoneum of nude mice after intraperitoneal injection. The influence of steroid hormones ( $E_{2}$ and progestin) was determined either by preincubating cultured cells before animal injection or by treating recipient mice. We provide evidence that optimal in vivo endometrial cell adhesion to the peritoneum requires both epithelial and stromal cells pretreated with $\mathrm{E}_{2}$. The addition of progestin did not counteract the effect of $\mathrm{E}_{2}$. Interestingly, the hormonal status of recipient mice did not influence the percentage of endometrial cell adhesion.

\section{MATERIAL AND METHODS}

\section{Endometrial Samples}

Human endometrium was obtained by biopsy aspiration from nonmenopausal women, 32-45 years of age, undergoing hysterectomy or laparoscopy for benign gynecological indications (subserosal leiomyomata, elective tubal ligation) and who did not receive any hormonal treatment. None of the patient had endometriosis. Nine different human samples have been used. Endometrial samples obtained throughout the menstrual cycle gave rise to similar results (five were in the proliferative phase, days 4-13, and four were in the secretory phase, days 1626). Approval for this study was obtained from the Institutional Review Board of the University of Liège (Liège, Belgium).

\section{Cell Culture and Treatment}

Biopsy specimens were placed immediately in ice-cold Hanks' Balanced Salt Solution (HBSS) supplemented with penicillin-streptomycin (100 IU/mL) (Gibco Life Technologies, Gaithersburg, MD) for transport to the laboratory. The tissue was gently trimmed into small pieces $\left(1-3 \mathrm{~mm}^{3}\right)$, washed in fresh medium, then incubated for 30 minutes at $37^{\circ} \mathrm{C}$ in a shaking bath in HBSS containing $0.1 \%$ collagenase type IA (Sigma, St. Louis). At the end of the incubation, cell clumps were mechanically dispersed by aspiration through a Pasteur pipette. After centrifugation, cells were collected in Dulbecco's modified eagle medium (DMEM)/ F12 (Gibco) and plated onto plastic $75 \mathrm{~cm}^{2}$ T-Flasks (Nunc, Roskilde, Denmark) at $37^{\circ} \mathrm{C}$ in $95 \%$ air $/ 5 \% \mathrm{CO}_{2}$. Cells were maintained in DMEM/F12 supplemented with 10\% desteroidized fetal bovine serum (FBS) (Gibco), penicillin-streptomycin (100 IU/mL), $5 \mu \mathrm{g} / \mathrm{mL}$ fungizone, $4 \mathrm{mM} \mathrm{L-glutamin,} 20 \mathrm{mM}$ Hepes, $10 \mu \mathrm{g} / \mathrm{mL}$ insulin, $5 \times 10^{-6} \mathrm{M}$ hydrocortisone, and $2 \mathrm{ng} / \mathrm{mL}$ epithelial growth factor (Sigma). After 3-5 days of culture, when cells became confluent, they were collected after detachment by trypsin-EDTA treatment and diluted to obtain a final concentration of $1.10^{6}$ cells $/ 100 \mu \mathrm{L}$ of serum-free medium. We therefore used primary cell culture and no passage was performed before injection to recipient animals. Hormonal treatments of cells were performed by culturing cells for 48 hours before injection to recipient animals in the presence of $E_{2}\left(10^{-8} \mathrm{M}\right)$ and/or progestin (nomegestrol acetate, $10^{-7} \mathrm{M}$ ). Nomegestrol acetate was obtained from Theramex (Monaco) and used in place of natural $\mathrm{P}$ because of its slower metabolization in culture.

\section{Cell Purification}

After enzymatic digestion, the cell suspension was filtered through a $250 \mu \mathrm{m}$ sieve in polypropylene (Sefar, Ruschlikon, Switzerland) to remove mucous material and undigested tissue. Cells were suspended in $10 \mathrm{~mL}$ fresh DMEM containing 10\% FBS. Single stromal cells were separated from clumps of epithelium by a 30minute period of differential sedimentation at unit gravity. The top $8 \mathrm{~mL}$ of medium (containing predominantly stromal cells) was slowly removed, and cells were collected by centrifugation $(300 \mathrm{~g})$. The stromal cells were again resuspended in $10 \mathrm{~mL}$ of fresh medium and sedimentation was repeated. Stromal cells from the second sedimentation were filtered through a 40- $\mu$ m nylon mesh filter (Becton Dickinson, San Jose, CA) to eliminate any remaining clumps of epithelial cells and allowed to adhere selectively to $25-\mathrm{cm}^{2}$ tissue culture dishes for 20 minutes, at $37^{\circ} \mathrm{C}$, in $95 \%$ air $/ 5 \% \mathrm{CO}_{2}$. Then the nonattached epithelial cells that were still present were removed and a purified stromal preparation was obtained.

For epithelial isolation, the bottom $2 \mathrm{~mL}$ of the first sedimentation media was collected and submitted to a second enzymatic digestion with $0.5 \%$ collagenase, $0.1 \%$ hyaluronidase, $0.1 \%$ pronase, $0.02 \%$ DNAse, and $2 \%$ FBS in HBSS, at $37^{\circ} \mathrm{C}$. After 20 minutes of digestion, the epithelial preparation was washed and layered over 10 
$\mathrm{mL}$ of fresh medium for two more 30-minute sedimentation periods. The bottom $2 \mathrm{~mL}$ of sedimentation media was filtered through a 40- $\mu$ m nylon mesh filter (Becton Dickinson, San Jose, CA), which retained epithelial cells. Purification of epithelial cells was achieved by allowing stromal cells (that attach rapidly to plastic) to adhere selectively to $25-\mathrm{cm}^{2}$ tissue culture dishes for $30-40$ minutes, at $37^{\circ} \mathrm{C}$, in $95 \%$ air $/ 5 \% \mathrm{CO}_{2}$. Nonattached epithelial cells were collected and plated onto plastic culture dishes (15-17).

For immunohistochemical analysis, stromal and epithelial cells cultured on $13 \mathrm{~mm}$ diameter Thermanox coverslips (Nunc, Naperville, Illinois) in 24 -well plates were fixed with methanol at $-20^{\circ} \mathrm{C}$.

\section{Injection of Human Endometrial Cells into Nude Mice}

Eight-week-old female ovariectomized BALB/c nu/nu mice (Iffa Credo, L'Arbresle, France) were used. Hormonal treatment consisted of implantation of subcutaneous 60-day release pellet of $\mathrm{E}_{2}$ and/or nomegestrol (Innovative Research of America, Sarasota, FL), the day before cell injection. Human cells $\left(1.10^{6}\right.$ in $100 \mu \mathrm{L}$ serum-free medium) were injected intraperitoneally with tuberculin syringes through 18-gauge needles. Mice were sacrificed 2 weeks later, and the abdominal peritoneum was removed from the level of the xiphoid superiorly to the pubic symphysis inferiorly. Peritoneum was extended laterally to the 3 and 9 o'clock positions and maintained flattened during formalin fixation, dehydration through graded ethanol, and embedding in paraffin. Histological and immunohistochemical techniques were used on five serial micrometer tissue sections to demonstrate the presence of endometrial cells attached to peritoneum. The entire peritoneum was sectioned and observed to detect any endometriotic-like lesion. Take rate was defined as the presence of endometriotic-like lesions consisting of glandular structure surrounded by stromal cells.

\section{Immunostaining}

Stromal and epithelial cells in culture were identified by classical immunocytochemistry using monoclonal antibodies raised against human cytokeratin 8-18 (Becton Dickinson, San Jose, CA) or human vimentin (clone V9, Dako, Glostrup, Denmark), respectively. Cell identification on tissue samples was performed by classical immunohistochemistry using a monoclonal anti-human cytokeratin/HRP or a rabbit anti-human P receptor both purchased from Dako (Glostrup, Denmark). Negative control included sections stained with a nonimmune serum in the absence of the primary antibody. Slides were reviewed by an anatomopathologist. To compare the histological appearance of endometriotic lesions developed in nude mice with those of women, a typical peritoneal endometriotic implant was obtained from a patient undergoing laparoscopy for infertility.

Figure 1: Morphology of mixed or pure cultures of epithelial and stromal endometrial cells. A, Mixed populations of stromal (arrow) and epithelial (double arrow) endometrial cells were cultured in vitro (x100). B, Immunoperoxidase staining with an antibody against cytokeratins 8-18 revealed positivity in epithelial cells (arrow) surrounded by negative stromal cells (x100). C, Immunoperoxidase staining with anti-cytokeratins 8-18 in monoculture of purified epithelial cells (x200) (black arrow). D, Immunofluorescence staining with antivimentin antibody in monoculture of purified stromal endometrial cells (x200) (white arrow).
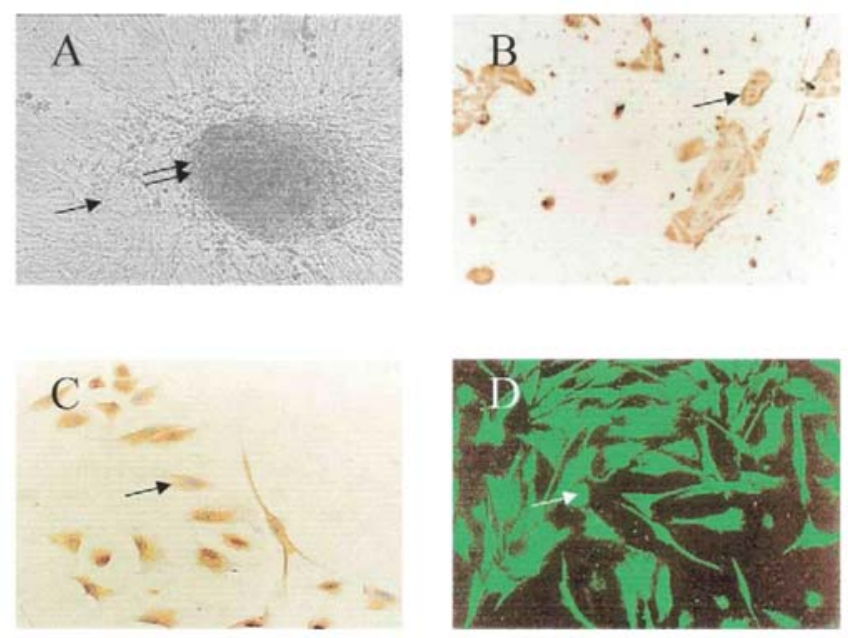
Table 1: Injection of purified monocultures or mixed populations of stromal and epithelial endometrial cells into $E_{2}$-supplemented nude mice.

\begin{tabular}{ll}
\hline Injected cells & Take rates $^{\mathbf{a}}$ \\
\hline Stromal cells & $0 / 10$ \\
Epithelial cells & $0 / 10$ \\
Stromal and epithelial cells & $5 / 10$ \\
\hline
\end{tabular}

${ }^{a}$ Number of mice with endometriotic-like lesion/number of injected mice. Endometriotic-like lesions were detected by histological analysis of mice peritoneum 2 weeks after cell injection into nude mice supplemented with $E_{2}$, as described in the Material and Methods section.

\section{Statistical Analysis}

Fisher's test has been applied to the results. $P<.05$ was considered statistically significant.

\section{RESULTS}

- In vivo adhesion of human endometrial cells to mice peritoneum required both epithelial and stromal cells.

- Mixed cultures of stromal and epithelial endometrial cells consisted of epithelial cell clusters surrounded by stromal cells (Fig. 1A). Epithelial cells accounted for 10\%-20\% and stromal cells for $80 \%-90 \%$, as assessed by immunostaining (Fig. 1B). Monocultures of epithelial endometrial cells or stromal endometrial cells were obtained after cell separation according to the procedure described in Material and Methods. In these conditions, cell purity was higher than 95\% (Fig. 1C and 1D).

- To evaluate the capacity of pure epithelial cells, pure stromal cells, or mixed epithelial and stromal cells to adhere in vivo to mice peritoneum, pure populations or mixed cultures, containing 1 million cells, were injected intraperitoneally to $\mathrm{E}_{2}$-supplemented mice. Histological examination of mice peritoneum revealed that no adhesion of endometrial cells was observed when epithelial or stromal cells were injected separately. In sharp contrast, endometriotic-like structures were detected in 50\% of animals injected with mixed populations of stromal and epithelial cells (Table 1). No difference in terms of attachment has been detected regardless of the day of the cycle on which the endometrium was taken.

- The endometriotic-like lesions observed in mice were characterized by a glandular structure lined with a cuboidal epithelium with some areas of ciliated metaplasia surrounded by cytogenic stroma containing few hemosiderin-laden macrophages. Such morphology was similar to that seen in women with peritoneal endometriosis (Fig. 2). The human origin of cells detected in the endometriotic-like structure in mice was demonstrated by specific staining with species-specific anti-human cytokeratin (Fig. 3A) and anti-human P receptor antibodies (Fig. 3C). A negative control showed the background staining of surrounding cells (Fig. 3B).

- Pretreatment of endometrial cells with $\mathrm{E}_{2}$, but not progestin, promoted in vivo adhesion

- Mixed cultures of stromal and epithelial cells were treated with progestin, $E_{2}$, or $E_{2}$ and progestin for 48 hours before injection into mice. The recorded rate of endometriotic-like lesion was 25\% without any cell treatment. Cell pretreatment with progestin did not affect this take rate $(P>.05)$. Preincubation of cells in culture with $\mathrm{E}_{2}$ gave rise to a significant enhancement of this take rate $\left(66 \%\right.$ in the presence of $E_{2}$ versus $25 \%$ in the absence of hormones) $(P<.05)$. A combined treatment with $\mathrm{E}_{2}$ and progestin neither potentiated nor reduced the effect of $\mathrm{E}_{2}$ on endometrial cell adhesion to mice peritoneum (70\%) (Table 2).

- The mice hormonal status did not influence endometrial cell adhesion in vivo.

- We next evaluated the influence of the hormonal status of recipient animals on endometrial cell adhesion to mice peritoneum. Before cell injection, ovariectomized mice were implanted with a pellet of progestin, a pellet of $E_{2}$, or both. The results presented in Table 2 demonstrate that the hormonal status of the recipient animal did not affect the rate of endometriotic-like lesions $(P>.05)$. Furthermore, it did not influence the histological aspects of these lesions (data not shown). 
Figure 2: Comparison between endometriotic cyst stained with hematoxylin-eosin in woman with peritoneal lesion of endometriosis $(A, x 50 ; B, x 400)$ and endometrial-like structures detected in nude mice injected with mixed populations of human stromal and epithelial endometrial cells (C, x50; D, x400).
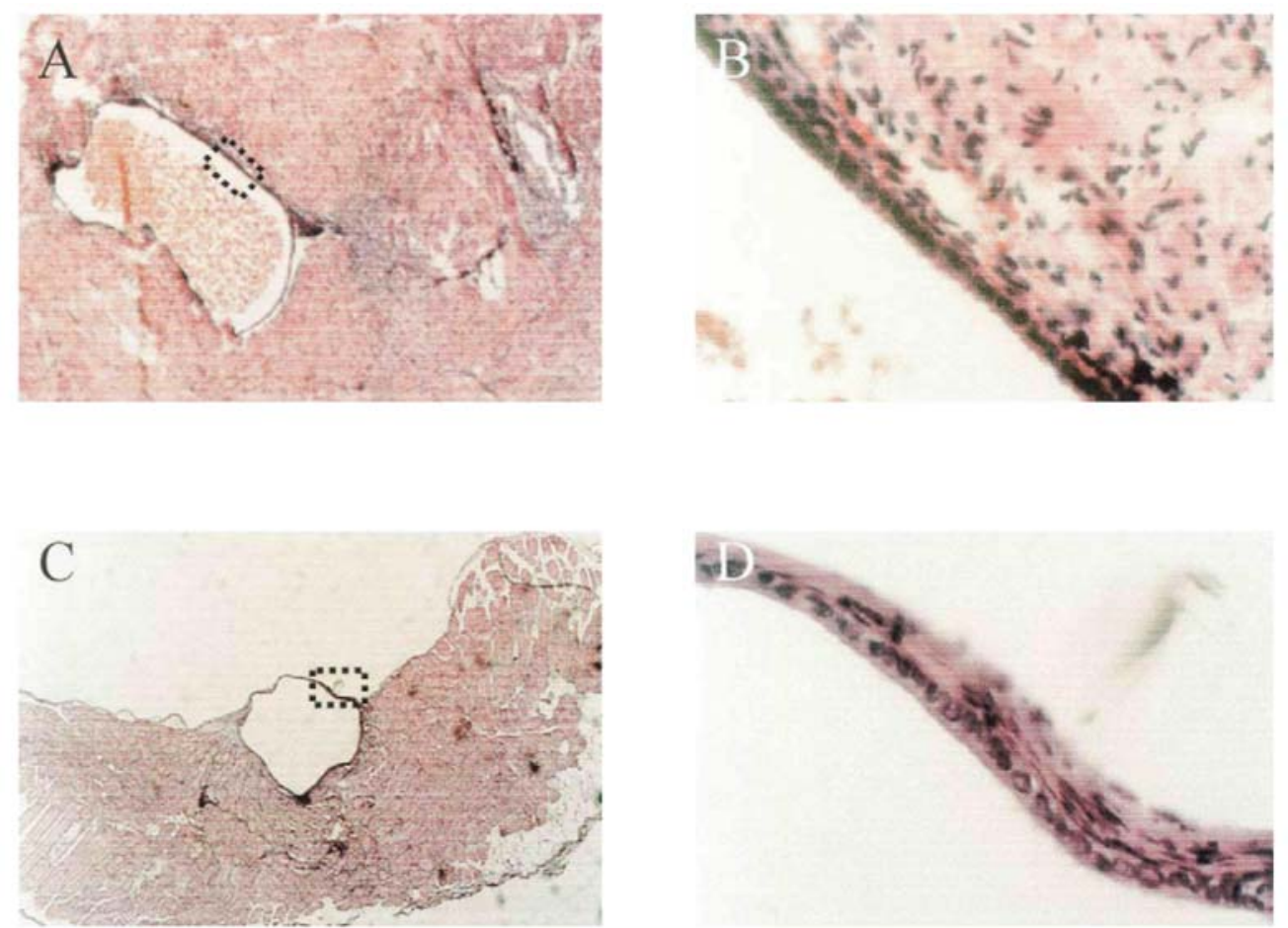

Figure 3: $E_{2}$-supplemented nude mice were injected with a mixed population of human stromal and epithelial endometrial cells. Immunoperoxidase stainings of human endometriotic-like lesions were performed with monoclonal species-specific anti-human cytokeratin/HRP (A), negative control (B), and rabbit anti-human $P$ receptor (C) (A and B, x200; C, x400).
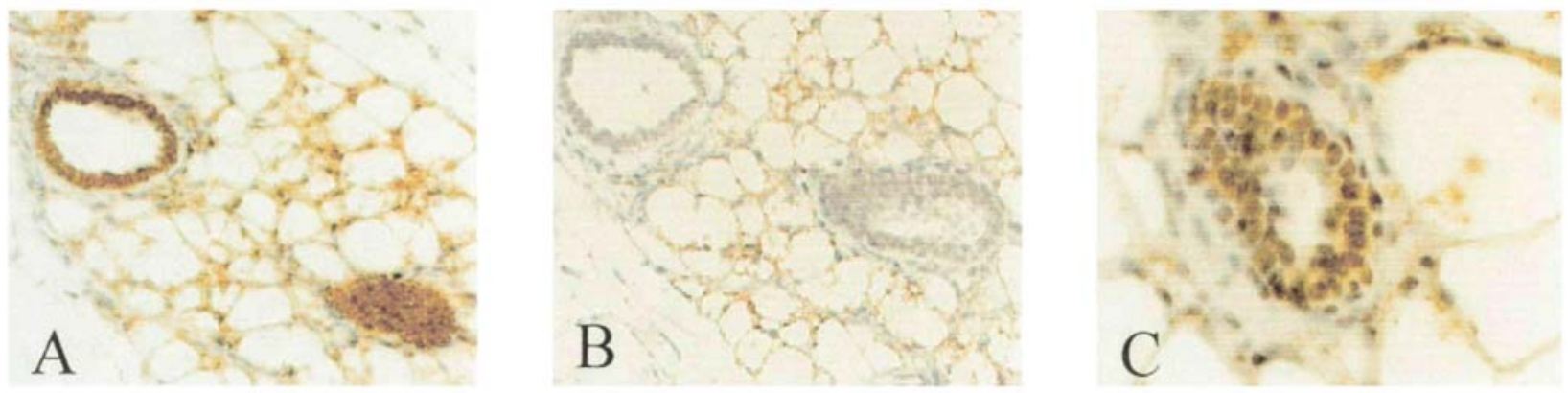
Table 2: Effects of steroid treatment on the endometrial cell adhesion to the peritoneum of nude mice.

\begin{tabular}{|c|c|}
\hline Group & Take rates $^{\mathrm{a}}(\%)$ \\
\hline I. Control & $5 / 20(25)$ \\
\hline \multicolumn{2}{|c|}{ II. Cell treatment } \\
\hline $\mathrm{P}$ & $4 / 10(40)$ \\
\hline $\mathrm{E}_{2}$ & $6 / 9(66)^{b}$ \\
\hline $\mathrm{E}_{2}+\mathrm{P}$ & $7 / 10(70)^{\mathrm{b}}$ \\
\hline \multicolumn{2}{|c|}{ III. Mice treatment } \\
\hline $\mathrm{P}$ & 3/10 (30) \\
\hline $\mathrm{E}_{2}$ & $5 / 10(50)$ \\
\hline $\mathrm{E}_{2}+\mathrm{P}$ & $5 / 10(50)$ \\
\hline \multicolumn{2}{|c|}{$\begin{array}{l}\text { Endometriotic-like lesions were detected by histological analysis of mice peritoneum } 2 \text { weeks after injection of mixed populations } \\
\text { stromal and epithelial endometrial cells. } \\
\text { I: Untreated mixed stromal and epithelial cell cultures were injected into untreated animals. } \\
\text { II: Mixed stromal and epithelial cell cultures were preincubated with } P, E_{2} \text {, or both }\left(E_{2}+P\right) \text { before IP injection into nude mice. } \\
\text { III. Mixed stromal and epithelial cell populations were injected into mice implanted with a pellet releasing } P, E_{2} \text { or both }\left(E_{2}+P\right) \text {. } \\
\text { a Number of mice with endometriotic-like lesion/number of injected mice. } \\
\text { b } P<.05 \text { versus control group. }\end{array}$} \\
\hline
\end{tabular}

\section{DISCUSSION}

Ectopic implantation of endometrial glands and stroma after retrograde menstruation is the most accepted theory of the pathophysiology of endometriosis (2). Sequentially, it involves (1) the dissemination of viable epithelial and stromal endometrial cells during menstruation via the fallopian tubes onto the abdominal cavity and (2) the implantation of these cells into the peritoneum leading eventually to endometriotic lesions. Endometrial tissue in peritoneal fluid consisted of glands with stroma, as well as of separated cells (18). For obvious accessibility reasons, endometriosis is very difficult to study in the affected patients, and animals, except primates, do not suffer from endometriosis. Therefore, the development of models of endometriosis is a prerequisite for addressing the disease etiology. Ideal models should take into account the different compartments involved in the development of endometriosis, namely, epithelial and stromal cells and the peritoneum.

Here we have attempted to evaluate the respective role of these different cell types in the ectopic adhesion of endometrial cells to the peritoneum and in the formation of endometriotic-like lesions. Previous morphological studies, using fresh fragments of endometrium, have described the adhesion of epithelial and stromal $(10,11$, 19). According to these studies, stromal cells are involved in the attachment of endometrial glandular cells. None of these studies were performed with isolated stromal and/or isolated epithelial cells.

We demonstrate for the first time that epithelial cells are unable to adhere and reorganize into structured glands without the presence of stromal cells. These data suggest that paracrine interactions between epithelial and stromal cells play a key role during endometrial ectopic implantation. According to the study of Nisolle et al. (10), the adhesion of endometrial stromal cells represents the initial step in the endometriosis process. One can speculate that such cooperation between epithelial cells and stromal cells involves a cross-talk between the two cell types through the secretion of growth factors, cytokines, and/or chemokines (20). Alternatively, the contribution of stromal cells to epithelial cell adhesion could be the secretion of extracellular matrix components or the release of proteases leading to extracellular matrix remodeling and formation of an appropriate microenvironment for epithelial cell implantation, proliferation, and organization into endometrial glands. Such epithelia-stromal cooperation has been demonstrated for the implantation of tumor cells in an ectopic site (2123).

In the second part of our study, we examined another putatively important factor for the development of endometriosis: the hormonal status of endometrial cells and that of the recipient animals. Here we clearly show that pretreatment of cells with $\mathrm{E}_{2}$ promoted the lesion take rate, while pretreatment with progestin alone did not affect cell implantation. These data are in agreement with those reported by Bruner et al. (12). However, their data differ markedly from ours regarding the combination of $E_{2}$ and progestin. Indeed, they recorded a dramatic inhibitory effect when endometrial expiants pretreated with combined hormones were injected in vivo. In contrast, in our experimental conditions, progestin did not affect the effect of $E_{2}$ on endometrial cell adhesion. One possible explanation for such a discrepancy is that, in three-dimensional expiant cultures, the $\mathrm{E}_{2}$ plus $\mathrm{P}$ could trigger mechanisms other than that in monolayer cell culture. 
One major finding in our study is that pretreatment of endometrial cells with $\mathrm{E}_{2}$ influenced lesion take rate, while administration of hormones to recipient animals had no effect. This observation emphasizes a crucial role of the endometrial cell hormonal status for cell adhesion.

In women, lesions corresponding to the early stage of endometriosis are well vascularized (24). The endometriotic-like lesions observed here after injection of endometrial cells did not show any neoangiogenesis. Factors other than sex steroid hormones probably play a key role in the growth and spreading of endometriosis. Local growth factors could regulate cell proliferation through autocrine or paracrine interactions $(25,26)$.

Altogether our data demonstrate that nude mice are convenient recipients to study early implantation events. However, the mouse peritoneal environment is unlikely to provide all the paracrine angiogenic stimuli required for successful neoangiogenesis. Nude mice are suitable recipients for human tissue transplantation because they lack the defensive T-lymphocyte system and therefore present low ability of cell-mediated immunity.

Nevertheless, we are aware of the limits of this model since thymus aplasia could also influence the presence of growth factors and cytokines in the peritoneal fluid.

In conclusion, our results give new insights into the understanding of endometriotic implantation. First of all, dispersed mixed endometrial cells are able to attach onto the peritoneum and lead to endometriotic-like lesions. Our data emphasize the importance of cooperation between epithelial and stromal cells for peritoneal implantation. Finally, $E_{2}$ pretreatment of cells but not of recipient animals improves the development of endometriotic lesions.

\section{Acknowledgments}

The authors thank Marie Rose Pignon, Patricia Gavitelli, Guy Roland and Fabrice Olivier for their technical assistance in cell culture, histology, and animal maintenance.

\section{References}

1. Dmowski WP, Radwanska E. Current concepts in pathology, histogenesis and etiology of endometriosis. Acta Obstet Gynecol Scand Suppl 1984;123:29-33.

2. Sampson JA. The development of the implantation theory for the origin of peritoneal endometriosis. Am J Obstet Gynecol 1940;40:449557.

3. Thomas EJ. Endometriosis: still an enigma. Br J Obstet Gynaecol 1993;100:615-7.

4. van der Linden PJ. Theories on the pathogenesis of endometriosis. Hum Reprod 1996;11(Suppl 3):53-65.

5. Keetel WC. The viability of the cast-off menstrual endometrium. Am J Obstet Gynecol 1951;61:440-1.

6. Koks CA, Groothuis PG, Dunselman GA, de Goeij AF, Evers JL. Adhesion of shed menstrual tissue in an in-vitro model using amnion and peritoneum: a light and electron microscopic study. Hum Reprod 1999;14:816-22.

7. Ho HN, Wu MY, Yang YS. Peritoneal cellular immunity and endometriosis. Am J Reprod Immunol 1997;38:400-12.

8. Aoki D, Katsuki Y, Shimizu A, Kakinuma C, Nozawa S. Successful heterotransplantation of human endometrium in SCID mice. Obstet Gynecol 1994;83:220-8.

9. Somigliana E, Vigano P, Rossi G, Carinelli S, Vignali M, Panina-Bordignon P. Endometrial ability to implant in ectopic sites can be prevented by interleukin-12 in a murine model of endometriosis. Hum Reprod 1999;14:2944-50.

10. Nisolle M, Casanas-Roux F, Donnez J. Early-stage endometriosis: adhesion and growth of human menstrual endometrium in nude mice. Fertil Steril 2000;74:306-12.

11. Witz CA, Monotoya-Rodriguez IA, Schenken RS. Whole expiants of peritoneum and endometrium: a novel model of the early endometriosis lesion. Fertil Steril 1999;71:56-60.

12. Bruner KL, Matrisian LM, Rodgers WH, Gorstein F, Osteen KG. Suppression of matrix metalloproteinases inhibits establishment of ectopic lesions by human endometrium in nude mice. J Clin Invest 1997;99:2851-7. 
13. Zamah NM, Dodson MG, Stephens LC, Buttram VC Jr, Besch PK, Kaufman RH. Transplantation of normal and ectopic human endometrial tissue into athymic nude mice. Am J Obstet Gynecol 1984; 149: 591-7.

14. Manyak MJ, Nelson LM, Solomon D, DeGraff W, Stillman RJ, Russo A. Fluorescent detection of rabbit endometrial implants resulting from monodispersed viable cell suspensions. Fertil Steril 1990;54:356-9.

15. Vigano P, Di Blasio AM, Dell' Antonio G, Vignali M. Culture of human endometrial cells: a new simple technique to completely separate epithelial glands. Acta Obstet Gynecol Scand 1993;72:87-92.

16. Osteen KG, Hill GA, Hargrove JT, Gorstein F. Development of a method to isolate and culture highly purified populations of stromal and epithelial cells from human endometrial biopsy specimens. Fertil Steril 1989;52:965-72.

17. Laird SM, Li TC, Bolton AE. The production of placental protein 14 and interleukin 6 by human endometrial cells in culture. Hum Reprod 1993;8:793-8.

18. Bartosik D, Jacobs SL, Kelly LJ. Endometrial tissue in peritoneal fluid. Fertil Steril 1986;46:796-800.

19. Witz CA, Thomas MR, Montoya-Rodriguez IA, Nair AS, Centonze VE, Schenken RS. Short-term culture of peritoneum expiants confirms attachment of endometrium to intact peritoneal mesothelium. Fertil Steril 2001;75:385-90.

20. Singer CF, Marbaix E, Kokorine I, Lemoine P, Donnez J, Eeckhout Y, et al. Paracrine stimulation of interstitial collagenase (MMP-1) in the human endometrium by interleukin lalpha and its dual block by ovarian steroids. Proc Natl Acad Sci USA 1997;94:10341-5.

21. Noel AC, Polette M, Lewalle JM, Munaut C, Emonard HP, Birembaut P, et al. Coordinate enhancement of gelatinase A mRNA and activity levels in human fibroblasts in response to breast-adenocarcinoma cells. Int J Cancer 1994;56:331-6.

22. Masson R, Lefebvre O, Noel A, Fahime ME, Chenard MP, Wendling C, et al. In vivo evidence that the stromelysin-3 metalloproteinase contributes in a paracrine manner to epithelial cell malignancy. J Cell Biol 1998;140:1535-41.

23. Noel A, Kebers F, Maquoi E, Foidart JM. Cell-cell and cell-matrix interactions during breast cancer progression. Curr Top Pathol 1999; 93:183-93.

24. Nisolle M, Casanas-Roux F, Anaf V, Mine JM, Donnez J. Morphometric study of the stromal vascularization in peritoneal endometriosis. Fertil Steril 1993;59:681-4.

25. Halme J, White C, Kauma S, Estes J, Haskill S. Peritoneal macrophages from patients with endometriosis release growth factor activity in vitro. J Clin Endocrinol Metab 1988;66:1044-9.

26. Surrey ES, Halme J. Effect of peritoneal fluid from endometriosis patients on endometrial stromal cell proliferation in vitro. Obstet Gynecol 1990;76:792-7. 